\title{
Autoria na cultura do presente: apresentação
}

Luciene Azevedo ${ }^{1}$

Cristian Molina 2

Paloma Vidal ${ }^{3}$

Este dossiê apresenta uma problematização dos modos de autoria na cultura do presente. Propondo curto-circuitos variados entre autor e obra, entre o livro e suas preparações, entre a obra e suas diversas circulações e suportes, entre criação, leitura e crítica, os textos reunidos neste dossiê mostram que tratar da autoria na cultura do presente implica estar disposto a lidar com "formas complexas", como sugere o crítico argentino Reinaldo Laddaga (2013, p.15). Ao mesmo tempo que podemos falar de um retorno do sujeito, não apenas em narrativas em que a voz autoral confunde-se com a do personagem, como acontece nas autoficções, mas também em relação à atuação dos autores na dinâmica de forças do sistema artístico como um todo, é notável um certo deslocamento da função autoral, se pensarmos, por exemplo, nas proposições de Kenneth Goldsmith e sua noção de escrita não criativa ou no papel dos curadores no campo das artes visuais. Se não podemos descartar tão facilmente o autor, já é possível notar uma reinvenção das práticas autorais e pensar a autoria não só como intensa performance de si, dentro e fora dos textos, mas também como certo "enfraquecimento da ansiedade autoral", como também sugere Laddaga (2007, p. 16, tradução nossa).

Assim como Goldsmith, Laddaga (2012) identifica o contemporâneo com um momento complexo de transformação do imaginário de produção artística em que é possível perceber a emergência do que chama de uma "outra cultura das artes". Nessa outra cultura, o sujeito não preserva apenas uma dimensão íntima, de autoconhecimento, mas passeia, faz anotações, monitora a si mesmo nas relações afetivas e

\footnotetext{
${ }^{1}$ Doutora em literatura comparada e professora da Universidade Federal da Bahia (UFBA), Salvador, BA, Brasil. (Dorcid.org/0000-0002-0224-6034. E-mail: aaluciene@ gmail.com

${ }^{2}$ Doutor em humanidades e artes e professor da Universidad Nacional de Rosario, Rosario, Santa Fé, Argentina. Dorcid.org/0000-0002-2087-2741. E-mail: molacris@yahoo.com.ar

${ }^{3}$ Doutora em letras e professora da Universidade Federal de São Paulo (Unifesp), Guarulhos, SP, Brasil. (Dorcid.org/0000-0003-4731-5707. E-mail: palomavidal@yahoo.com
} 
intelectuais, na sua relação com a obra e com a crítica, sendo que esse "monitoramento" pode se tornar parte da obra, o que contribui para constituir um "regime prático" no qual prevalecem "objetos fronteiriços" (Laddaga, 2012, p. 289) que fazem vacilar o regime moderno da autonomia estética. Valorizam-se nesse regime a ideia de inacabamento, de processo, da obra como um arcabouço, inacabado, em processo. A esse procedimento Laddaga (2013, p. 13) caracteriza como uma "visita ao estúdio", a possibilidade de o próprio texto desvendar sua "casa de máquinas" para o leitor. Agora, não mais no sentido adorniano, tal como apontado no clássico texto "Posição do narrador no romance contemporâneo", mas no sentido de que é possível observar o sujeito realizando um trabalho de curadoria de si próprio e de sua obra, recriando anotações, lembranças, vivências na reconstrução da pessoa que se imagina que se é ou foi, expondo-se à precariedade do procedimento que torna indistinguíveis o processo e o produto.

A "nova cultura das artes", para retomar os termos de Laddaga, gera novos problemas nas relações do autor com o mercado. Em Muerte y resurreción del autor, Marcelo Topuzian se pergunta quais são os modos do retorno do autor no presente, após suas sucessivas mortes desde a década de 1960, especialmente no campo da teoria literária francesa, com Barthes, Derrida ou Foucault, cuja influência nas literaturas da América Latina (e na sua crítica) é muito forte. Topuzian argumenta que a "função de autor" torna-se porosa nas novas condições, uma vez que funciona como um logotipo comercial numa rede tecnológica e de mercado. Como pensar as relações complexas entre autoria, redes sociais e mercado, então, em um mundo onde a literatura e as artes, segundo Graciela Montaldo (2017), tendem a produzir objetos que se tornam bens similares às mercadorias, com uma obsolescência acelerada? Que possibilidades críticas e artísticas a noção de autor encontra na contemporaneidade quando se assemelha, cada vez mais, a uma marca comercial que aproveita o aparelho de consumo capitalista através da fectichização de um nome associado a uma prática ou a um procedimento quase autorreferencial? Seria possível pensar não tanto em uma função de autor que seja mera assimilação à lógica da rotulação mercantil, mas em um gesto autoral complexo - nos termos de Giorgio Agamben em seu Profanações - que, ao revelar suas potencialidades culturais, 
sem finalidade clausurada, desclassifica as atribuições de si, para gerar válvulas de escape à sua mera funcionalidade mercantil?

É na direção dessas discussões e perguntas que vão alguns dos textos deste dossiê, começando por "Poesia, documento, autoria", de Diana Klinger, que discute a afirmação de Ana Cristina César de que "literatura não é documento" e a assertiva de Kenneth Goldsmith de que o "contexto é o novo conteúdo". A partir delas, ela lê livros de Carlito Azevedo e Roy Frankel, em diálogo e em contraste com exemplos variados das artes e da literatura a partir das vanguardas, para investigar, conjuntamente, a composição do livro enquanto "mídia sobrevivente" e os usos que a poesia faz de diferentes tipos de documentos. O que emerge daí são as transformações na noção de autor, que se apresenta cada vez mais na forma de alguém que organiza materiais alheios, em vez de falar em nome de um eu, e que se relaciona com o real de um modo desencontrado. "Na mudança de contexto de uma fala, na perda da relação com o sujeito de sua enunciação, na mistura com outras vozes ou instâncias de produção do mesmo discurso, a percepção do fragmento do real para o que o documento aponta vai sendo redimensionada", escreve Klinger.

O texto de Rodrigo Cerqueira, "Literatura como projeto", valendo-se dos pressupostos de Pierre Bourdieu, investiga a trajetória de Luiz Ruffato no campo literário brasileiro e a performance do autor em entrevistas, para relacionar a construção da figura do autor a um projeto de obra, a pentalogia Inferno Provisório, chamando a atenção para o fato de que a autorrepresentação do autor, a legitimação por parte da crítica e a elaboração da obra andam lado a lado, num processo de "constante negociação com o campo, inaugurando novas disputas que consolidam seu lugar específico nesse espaço de produção ou renovam esse lugar, reformulam seu próprio local de enunciação". Esse movimento de negociação, que envolve, entre outros aspectos, a insistência na relação entre vida e obra, se dá através de muitos avanços e recuos, concordâncias e desvios, que podem criar novas formas de ler e escrever uma obra.

A problematização da autoria se dá no texto "'Ninguém' é o nome do autor: Leonardo Gandolfi e Ana Martins Marques sobre a Odisseia", de Filipe Manzoni, através do diálogo que os poetas em questão mantêm com a tradição homérica. Privilegiando a cena em que, ao ter seu nome indagado pelo ciclope Polifemo, Ulisses se diz 
"ninguém", repensam-se tópicos caros ao contemporâneo, como o acolhimento tranquilo da tradição (sem a negatividade moderna) e o procedimento da apropriação como indício de afirmação das vozes dos poetas contemporâneos, pensada como uma "desautorização", que funciona como alternativa a um paradigma autoral. Analisamse, assim, poemas dos livros Escala Richter (2015), de Gandolfi, e A vida submarina (2009), de Marques, em que a Odisseia, narrativa fundadora da história ocidental, é reencenada, "como um 'texto' que é uma urdidura ainda sem arremate, isto é, como uma jornada de reconquista do nome que ainda não está concluída". A "reconquista do nome", que se dá através da releitura do poema homérico, entendido como um embate aberto, permite pensar "o contemporâneo como um tempo ainda sem nome para si mesmo".

Retomando e relendo os textos clássicos sobre autoria da teoria literária francesa, como os já mencionados Barthes e Foucault, Rejane Rocha, no texto "Textos que dão voltas por aí: Borges, Katchadjian, obra e autoria na literatura contemporânea", analisa a web como um circuito de circulação da literatura, apostando no pressuposto de que o suporte virtual altera a forma de compreensão da autoria. Para tanto, vale-se do polêmico livro El aleph engordado, do argentino Pablo Kachatdjian, e narra as agruras judiciais que o autor teve de enfrentar ao se apropriar do conto de Borges, para discutir o que chama de "patrimonialização" do nome e da obra do autor consagrado. Propõe Rocha: "se o pós-estruturalismo questionou a origem e a originalidade, rasurando a autoridade do autor e do texto "primeiro" - algo que a ficção pós-modernista explorou e explora como um dos seus traços recorrentes -, o contexto digital e a cibercultura levam ao paroxismo tais questionamentos e rasuras, já que artistas plásticos, músicos, escritores e leitores adquirem, cada vez mais, possibilidades técnicas e posturas ideológicas que fazem com que o compartilhamento, os recortes, as montagens não sejam mais - talvez não apenas - procedimentos de rebeldia estética, mas o ramerrão da produção cultural da atualidade".

O rascunho, os materiais de preparação para a escrita, já são obra? A pergunta é respondida afirmativamente por Ana Kiffer, no texto "O rascunho é a obra: o caso dos cadernos", que discute as fronteiras entre a obra e sua preparação a partir dos cadernos de Antonin Artaud. Assumindo uma dicção ensaística que aposta no 
híbridismo entre crítica e biografia, Kiffer debruça-se sobre um objeto difícil de definir, entre cadernos de escrita e cadernos de desenho, que habita "esse limbo da criação", num material que transborda do papel, em formas inesperadas e inclassificáveis, que desafiam radicalmente seus leitores. "É assim que esse profundo processo de instabilização das certezas por que passa o escritor é devolvido aos seus leitores", escreve Kiffer. Ela assinala também que os cadernos desestabilizam nosso olhar crítico, na medida em que questionam a relação entre "singularidade" e "excepcionalidade", acrescentando a esse binômio a "precariedade dos processos subjetivos que envolvem a criação". Finalmente, a partir dos cadernos, seria necessário repensar "os contornos que definem hoje o que é ser escritor ou artista, ou quem detém esse corpus discursivo que delineia contornos estético-políticos numa determinada época e lugar, e quem ascende ou não a essa posição - por conseguinte, um desarranjo no status quo dos espaços literários, artísticos, culturais".

Finalmente, o texto de Maria Fernanda Pinta e Irina Garbatzky, "Ante el teatro, en el museo, desde el archivo: modos escénicos (y autorales) del arte contemporáneo", investiga as aproximações entre o teatro e o arquivo nas artes visuais contemporâneas, explorando em dicção ensaística suas atuações como curadoras da mostra Mínimo Teatral, exibida no Museu Macro de Rosario, cidade argentina, em 2017. Elas comentam o processo de montagem da exposição e problematizam as relações entre a curadoria e a autoria, no sentido de indicar, por um lado, que as próprias "obras" teatrais selecionadas já se apresentavam como "un prisma que habilitaba un pensamiento sobre tiempos heterogéneos, narraciones parcialmente recuperadas, interrogaciones al canon de lo contemporáneo, señalamientos sobre las representaciones de la corporalidad y la subjetividad", num horizonte de pós-autonomia e de pós-produção, seguindo as reflexões de Bourriaud; e por outro, que o trabalho de curadoria também se configurou como um trabalho coletivo, questionando, nesse sentido, a centralidade autoral que teria se deslocado, nos últimos tempos, do autor propriamente para o curador. O resultado é, assim, uma exposição que abre o museu para um arquivo por sua vez aberto pela cena teatral.

Encerramos este dossiê com a entrevista realizada por José Veranildo Junior, através da qual podemos conhecer um pouco melhor o trabalho 
do coletivo literário Ariel e acompanhar as reflexões sobre a concepção da exposição Corpo-Poema. Os poemas inscritos na pele de mulheres fotografadas nuas criam uma tensão entre palavra e corpo, política e estética, segundo as entrevistadas, Thays Albuquerque e Marília Cacho, respectivamente idealizadora e fotógrafa do projeto.

\section{Referências}

ADORNO, Theodor (2003). Posição do narrador no romance contemporâneo. In: ADORNO, Theodor. Notas de literatura I. Tradução e apresentação de Jorge de Almeida. São Paulo: Duas Cidades; 34.

AGAMBEN, Giorgio (2007). Profanações. Tradução de Selvino J. Assman. São Paulo: Boitempo.

GOLDSMITH, Kenneth (2011). Uncreative writing. Managing language in the digital age. New York: Columbia University Press.

LADDAGA, Reinaldo (2007). Espectáculos de realidad. Ensayo sobre la narrativa latinoamericana de las dos últimas décadas. Buenos Aires: Beatriz Viterbo.

LADDAGA, Reinaldo (2012). Estética da emergência: a formação de outra cultura das artes. Tradução de Magda Lopes. São Paulo: Martins Fontes.

LADDAGA, Reinaldo (2013). Estética de laboratório: estratégias das artes do presente. Tradução de Magda Lopes. São Paulo: Martins Fontes.

MONTALDO, Graciela (2017). Ecología crítica contemporánea. Cuadernos de Literatura, Bogotá, v. 21, n. 41, p. 50-61.

TOPUZIAN, Marcelo (2014). Muerte y resurrección del autor (1963-2005). Santa Fe: UNL. 